\title{
Recent perspectives in neurology
}

\author{
Tjalf Ziemssen · Alexander Storch
}

Published online: 14 July 2013

(c) Springer-Verlag Wien 2013

This supplementum of the Journal of Neural Transmission is a collection of review articles demonstrating the advances in the field of clinical neurology over the last decades. This issue covers neurodegenerative diseases as well as neuroinflammatory, neurovascular and neuromuscular diseases up to stem-cell therapy and prospects for neuroprotection and neuroregeneration. This special issue is dedicated to the work of Professor Heinz Reichmann, Professor of Neurology at the Dresden University Clinic Carl Gustav Carus, Germany at the occasion of his 60th birthday. Many of Professor Reichmann's colleagues have contributed manuscripts to this issue. The broad range of topics demonstrates the fascination of clinical neurology which was brought to Dresden by Professor Reichmann in the last 17 years.

Professor Reichmann is the Professor of Neurology and Dean of the Medical Faculty at Dresden University of Technology, Dresden, Germany. As well as being a member of numerous scientific societies, including The Movement Disorder Society (MDS), the European Neurological Society (ENS) and the American Academy of Neurology (AAN), he is a past President of the German

T. Ziemssen $(\bowtie)$

Department of Neurology, Center of Clinical Neuroscience, University Hospital Carl Gustav Carus, Dresden University of Technology, Fetscherstr 74, 01307 Dresden, Germany e-mail: Tjalf.Ziemssen@uniklinikum-dresden.de

A. Storch

Division of Neurodegenerative Diseases, Department of Neurology, Dresden University of Technology, 01307 Dresden, Germany

A. Storch

German Center for Neurodegenerative Diseases (DZNE)

Dresden, 01307 Dresden, Germany
Neurological Society (DGN) and the German Parkinson's Society (DPG), and currently serves as President of the ENS. He is member of numerous editorial boards such as of the European Journal of Neurology, the Journal of Neural Transmission, Acta Myologica and Aktuelle Neurologie. In 2010, he was honoured by becoming a Fellow of the Royal College of Physicians (FRCP).

Professor Reichmann's research involves biochemical and genetic analyses of energy metabolism, particularly in neurodegenerative disorders such as Parkinson's disease as well as mitochondrial cytopathies (Reichmann et al. 1986, 1993; Reichmann 1988; Lestienne et al. 1990, 1991). He has published more than 280 original papers in peerreviewed journals. In the recent years, he is following on numerous clinical aspects and the gut-to-brain hypothesis in the pathophysiology of Parkinson's disease (Pan-Montojo et al. 2010, 2012; Reichmann 2011; Haehner et al. 2009; Jost and Reichmann 2011). His work thus largely contributes to our current understanding of the involvement of mitochondrial function and dysfunction in the etiopathophysiology of various neurological diseases.

The extraordinary role of Professor Reichmann is represented well in this special issue with contributions from many of his collaborators and current team members in Dresden. This volume is thus intended to serve as a state of the art reference to demonstrate the fascination and advances of neurology and neuroscience in the last years.

We congratulate Heinz Reichmann on his 60th birthday and sincerely thank him for his many valuable and ongoing contributions to the scientific and political field of clinical neurology. We wish him many more successful and fruitful years to come. We thank all authors of this volume for their excellent contributions, as well as the managing editor, Christian Riederer, and Springer Publisher, Vienna, New York, for their help in publishing this special issue. 


\section{References}

Haehner A, Hummel T, Reichmann H (2009) Olfactory dysfunction as a diagnostic marker for Parkinson's disease. Expert Rev Neurother 9(12):1773-1779. doi:10.1586/ern.09.115

Jost W, Reichmann H (2011) Parkinson's disease: a multi-faceted disease. J Neurol 258(Suppl 2):S297-S298. doi:10.1007/s00415011-6017-X

Lestienne P, Nelson J, Riederer P, Jellinger K, Reichmann H (1990) Normal mitochondrial genome in brain from patients with Parkinson's disease and complex I defect. J Neurochem 55(5):1810-1812

Lestienne P, Nelson I, Riederer P, Reichmann H, Jellinger K (1991) Mitochondrial DNA in postmortem brain from patients with Parkinson's disease. J Neurochem 56(5):1819

Pan-Montojo F, Anichtchik O, Dening Y, Knels L, Pursche S, Jung R, Jackson S, Gille G, Spillantini MG, Reichmann H, Funk RH (2010) Progression of Parkinson's disease pathology is reproduced by intragastric administration of rotenone in mice. PLoS ONE 5(1):e8762. doi:10.1371/journal.pone.0008762
Pan-Montojo F, Schwarz M, Winkler C, Arnhold M, O'Sullivan GA, Pal A, Said J, Marsico G, Verbavatz JM, Rodrigo-Angulo M, Gille G, Funk RH, Reichmann H (2012) Environmental toxins trigger PD-like progression via increased alpha-synuclein release from enteric neurons in mice. Scientific reports 2:898. doi: 10.1038/srep00898

Reichmann H (1988) Enzyme activity measured in single muscle fibers in partial cytochrome c oxidase deficiency. Neurology 38(2):244-249

Reichmann H (2011) View point: etiology in Parkinson's disease. Dual hit or spreading intoxication. J Neurol Sci 310(1-2):9-11. doi:10.1016/j.jns.2011.04.016

Reichmann H, Rohkamm R, Zeviani M, Servidei S, Ricker K, DiMauro S (1986) Mitochondrial myopathy due to complex III deficiency with normal reducible cytochrome $\mathrm{b}$ concentration. Arch Neurol 43(9):957-961

Reichmann H, Lestienne P, Jellinger K, Riederer P (1993) Parkinson's disease and the electron transport chain in postmortem brain. Adv Neurol 60:297-299 